\title{
Spinal Arteriovenous Fistulas
}

\author{
Mohammad R. Rasouli, Vafa Rahimi-Movaghar and \\ Alexander R. Vaccaro
}

Additional information is available at the end of the chapter

http://dx.doi.org/10.5772/56729

\section{Introduction}

Spinal cord vascular lesions can be broadly classified into one of the 3 following groups: neoplasm (hemangioblastomas and cavernous malformations), aneurysms, and arteriovenous malformations (AVM).[1],[2] Spinal AVMs account for $1 \%$ to $2 \%$ of vascular neurologic pathologies and $3 \%-12 \%$ of space-occupying pathologies of the spinal cord.[3]

Several classifications have been proposed for spinal AVMs.[2],[4]-[6] They can be divided into intramedullary AVMs and arteriovenous fistulas (AVFs). Based on anatomical characteristics, spinal AVFs are classified as extradural AVFs and intradural lesions, including spinal dural AVFs (SDAVFs) and perimedullary spinal AVFs (PMAVFs).[7],[8] Rangel-Castilla et al. classified extradural AVFs as type A or type B based on the availability of intradural venous drainage. In Type A spinal extradural AVFs, there is intradural venous drainage and arteriovenous shunting develops in the epidural space. Type B can be further classified as B1 and B2, both of which are limited to the epidural space without any intradural draining veins. The only difference between these two types is the presence or absence of compression on the spinal cord and nerve roots.[9] There is a paucity of literature about spinal AVFs and due to the very small incidence of these lesion, almost all available studies are small cases series. However, spinal AVFs can manifest with severe neurologic symptoms, leading to permanent neurologic deficit. Therefore, in this chapter we aim to review the available literature about spinal AVFs.

\section{Literature search}

A literature search of Medline through PubMed was performed using following search terms: ("Arteriovenous Malformations"[Mesh] OR "Arteriovenous Fistula"[Mesh]) AND "Spinal 
Cord." Then we limited our search to English-language articles and studies on human subjects. We expanded our literature search using the "related citation" option in PubMed. We also searched Google Scholar using the following keywords: spinal, arteriovenous fistula, extradural arteriovenous fistula, spinal dural arteriovenous fistula, and perimedullary spinal arteriovenous fistula. We also manually searched the reference lists of important papers to identify those that we missed during our primary electronic search. Data on epidemiology, classification, etiology, clinical manifestations, diagnosis, management, prognostic factors, and outcome of SDAVFs were extracted from selected articles.

\section{SDAVFs}

Although SDAVFs are rare, they are the most common spinal vascular malformation and are responsible for $70 \%$ of spinal cord arteriovenous shunts,[10] with an annual incidence of 5-10 cases per million.[11] It has been suggested that SDAVFs are acquired lesions, though their exact etiology remains unknown. SDAVFs are seen more frequently in elderly males and tend to affect the thoracolumbar segment more frequently than other spinal segments.[10]

SDAVFs are low-flow lesions and cause venous hypertension and chronic spinal cord hypoxia. Patients present with progressive myelopathy. Paraparesis is often the initial presentation, which is followed by root and/or back pain, sensory impairment, and sphincter dysfunction. [7]Due to non-specific presentations, SDAVFs are often diagnosed late. The mean time interval between onset of symptoms and diagnosis of SDAVF has been reported as high as 22.9 months (range 12 to 44 months).[12]-[14] Some authors suggest that there is a correlation between time until diagnosis of SDAVF and severity of symptoms.[5],[15] As mentioned earlier, the majority of authors consider SDAVFs to be acquired lesions and that they should be differentiated from congenital intradural PMAVFs.[16]

Digital subtraction angiography is the gold standard for diagnosis of spinal vascular malformations, including SDAVF[17]; however, magnetic resonance imaging (MRI) has been suggested as an accurate and reliable tool for diagnosis of SDAVF.[7] Intramedullary highintensity changes on T2-weighted MRI are seen when SDAVF is present.[18] After treatment of SDAVF, intramedullary high-intensity changes start to reduce in the majority of cases between 1 and 4 months after treatment and these changes disappear in most cases between 2 weeks and 23 months after treatment. Although there is a possible correlation between the severity of these changes and preoperative neurologic deficits, there is not necessarily an association between reduction of intramedullary changes and clinical improvement.[18] One of the radiologic findings correlating with severity of functional status of patients with SDAVF is craniocaudal extension of the enlarged intrathecal draining veins.[19] For diagnosis of residual or recurrent flow in peri- or intramedullary vessels after treatment of SDAVFs, magnetic resonance angiography (MRA) may be more sensitive than MRI.[20]

SDAVFs can be treated surgically, endovascularly embolized, or a combination of surgery and endovascular techniques may be used.[21],[22] Traditionally, surgery is considered the treatment of choice for SDAVFs. If the lesion can be localized using imaging studies preoper- 
atively, surgery can be performed with a low complication rate.[22] In comparison, endovascular approaches are less invasive. However, surgery has an advantage over endovascular techniques when there are multiple SDAVFs because surgery provides direct visibility of all feeding vessels. Since the first case of surgical treatment of SDAVF in 1916,[23] advances in treatment have led to simplified techniques and good outcomes. Nowadays, the typical surgical approach consists of a posterior approach with a laminectomy or hemilaminotomy. The dura is opened, the arterialized vein is identified, and either cauterization or microscissor interruption of the SDAVF is performed.[13],[24],[25] Compared to clipping the draining vein alone, excision or coagulation of the nidus and disconnection of the draining vein may be associated with more favorable long-term results.[26] Complications following surgery are rare; however, instability after laminectomy and pseudomeningocele are two potential complications that can be minimized by limited facet removal $(<50 \%)$ and meticulous closure of the dura, muscle, and skin.[24]

Endovascular techniques are less invasive and preserve spinal cord tissue and its function; in some cases, access to the feeding vessels of SDAVFs is not possible endovascularly.[22] The first case of SDAVF embolization using metal pellets was described in 1968 by Doppman et al. [27] Since then, new agents including polyvinyl alcohol (PVA), isobutyl-2-cyanoacrylate (IBCA), and N-butyl cyanoacrylate (NBCA) have been introduced and used for endovascular embolization of various vascular lesions including SDAVF.[13] Although the rate of recanalization following use of PVA was high (up to 93\%),[28] the success rate of SDAVF embolization increased to 70\%-90\% using NCBA.[13] Ethylene vinyl alcohol (Onyx, EV3) liquid embolic system has also been used for embolization of SDAVFs. Onyx was approved by the Food and Drug Administration to be used for embolization of intracranial AVMs but has been used for treatment of spinal AVFs in recent years.[29]-[31] Onyx, which is a nonadhesive liquid agent, carries the advantages of lower likelihood of adhesion of the catheter to the vessels, which facilitates the injection of a larger amount of the agent.[30] In a small series of 3 SDAVFs, Nogueira et al. reported successful management of SDAVF without evidence of residual or recurrent AVF confirmed clinically and radiologically (MRI and MRA) during follow up of more than 7 months.[29] In another small series of 6 patients with SDAVF, Carlson et al. reported complete occlusion of AVF in 5 of the patients during 2 to 4 months of follow up using the Onyx embolization system.[32] It seems that in the future, Onyx will be the preferred embolization method for management of SDAVFs.

In a 2004 meta-analysis, Steinmetz et al. suggested that for treatment of SDAVF, surgery might be superior to embolization. Surgery is usually successful and recurrence and complications are rare. The authors also suggested that endovascular intervention might be a reasonable initial option; however, this technique is associated with a relatively high rate of recurrence. [24] Nowadays, in spite of significant improvements in endovascular embolization and the introduction of new embolization agents, surgery still seems to be the treatment of choice.[13] After treatment, the majority of patients experience improvement; however, symptoms may remain unchanged or deterioration might occur in a few cases.[24],[33] Overall, if timely treatment occurs, patient outcomes for motor abilities and gait disability scores will be particularly good.[34] However, if urinary dysfunction occurs, it less likely responds to 
treatment.[35] It seems that time from onset of symptoms to treatment is the largest determinant of outcome in patients with SDAVF.

\section{PMAVFs}

In 1977, Djindjian and colleagues described PMAVFs for the first time. They described PMAVF as abnormal direct connections between the anterior spinal artery and/or posterior spinal artery and the medullary veins without any intervening nidus.[36] PMAVF is located on the pial surface of the spinal cord. Later, Heros et al. considered PMAVFs to be type IV spinal vascular malformations.[37] PMAVFs can be classified into type I, type II, or type III according to the size of the fistula, the number of feeding arteries, and the severity of venous hypertension.[6],[38]-[40]

Type I is a small and single AVF which is fed by the terminal segment of a thin anterior spinal artery. The anatomic location of the AVF is against the anterior surface of the conus medullaris or the filum terminale. Draining perimedullary veins are slightly dilated. Type I AVFs are hemodynamically similar to SDAVFs.

Type II is an intermediate-sized AVF and is fed by multiple arteries. The anatomic location of the AVF is against the conus medullaris. The shunt may be found more frequently in a posterolateral position and less frequently in the anterior position. In the posterolateral position, the feeding artery originates from ipsilateral posterior spinal artery. In anteriorlylocated AVFs, the feeding artery originates from the anterior spinal artery. The AVF drains directly to a dilated and tortuous venous system containing a relatively high flow of arterialized blood. However, venous drainage in type II AVFs is slow.

Type III AVFs are large and single and located at the cervical or thoracic spinal cord. The AVF is fed by multiple arteries originating from the anterior and posterior spinal arteries. Highflow AVF drains to a very dilated and tortuous venous system.

The etiology of PMAVF is not clear. Although it is believed these lesions are congenital,[16] few cases of traumatic PMAVF have been reported in the literature.[39],[41] PMAVF is usually diagnosed between the third and sixth decades of life and are very rare, particularly in children. [42]The exact prevalence of PMAVFs is unknown but it is estimated that they constitute $4 \%-40 \%$ of spinal AVMs.[43],[44] Although the thoracolumbar spinal cord is the most common site of PMAVFs, these lesions can be seen at cervical and thoracic levels as well.[32]

PMAVFs are high-flow lesions leading to venous hypertension.[7] PMAVFs manifest with progressive myelopathy in the majority of patients and can result in complete transverse myelopathy if treatment does not occur.[44]Subarachnoid hemorrhage has also been reported in PMAVF cases.[39],[45] Due to non-specific presentation, the time from onset of symptoms to diagnosis may vary from 2 to 25 years.[46] Angiography is still the gold standard for diagnosis of PMAVF and its benefits include possible simultaneous treatment. However, angiography is invasive and time-consuming, and is only available in specialized centers. 
Recent studies indicate that MRI has high sensitivity for diagnosis of spinal AVFs.[7] It is recommended that MRI be ordered as the initial imaging study, followed by MRA if necessary.

PMAVFs can be treated surgically, with endovascularly embolized, or combination of techniques can be performed.[47]-[50] Early diagnosis and treatment may be associated with better results and may prevent irreversible spinal cord injury. Removal of shunt vessels while the spinal cord perfusion is preserved is the purpose of surgery; however, sometimes complex vasculature of the shunt and risk of spinal cord perfusion impairment make surgery complicated. Therefore, various intraoperative diagnostic tools should be used to appropriately identify shunt vessels to avoid damaging spinal cord perfusion. Spinal cord angiography, Doppler ultrasound, and videoangiography using indigo carmine and indocyanine green are some of these modalities.[51]-[53]

Due to the paucity of literature on PMAVF, which results from the very low incidence and prevalence of these lesions, it is not possible to standardize surgical approaches for these lesions; therefore, a variety of surgical approaches have been used for management of them. [45],[54]-[56] For treatment of giant PMAVFs, a combination of surgery and endovascular embolization is recommended.[57],[58] Embolization of PMAVF can be performed using glue, coils, and balloons.[47],[50],[57] Overall, treatment of PMAVFs is more difficult than treatment of SDAVFs.[38] Because the majority of PMAVFs are high-flow shunts, endovascular embolization should be considered as the initial therapeutic modality in pediatric patients.[47] In summary, surgery is successful in the treatment of PMAVFs, even in cases with involvement of the anterior spinal artery. In high-flow PMAVFs, endovascular embolization is an appropriate adjunct to surgery.[59]

\section{Extradural AVFs}

Extradural AVFs are the least frequent type of spinal AVFs. In spinal extradural AVFs, a direct connection exists between the artery or arteries and the extradural venous plexus, which is not available in normal individuals. This abnormal connection is located within the spinal canal and/or intervertebral foramen. Extradural AVFs can cause venous hypertension, mass effect, and vascular steal leading to myelopathy.[8]

Type A extradural spinal AVFs usually manifest as congestive myelopathy or cauda equina syndrome based on the location of the AVF; however, type B1 extradural spinal AVFs present with spinal cord or nerve root compression. Type B2 extradural AVFs are asymptomatic. [30]MRI findings in Type A spinal extradural AVFs are spinal cord edema and perimedullary flow voids. On T2-weighted images, spinal cord edema (hyperintensity) is seen over multiple segments with a hypointense rim, most likely indicating deoxygenated blood.[8] In contrast, type B2 spinal extradural AVFs are difficult to diagnose with MRI and spinal angiography is the imaging modality of choice for diagnosis of these lesions.

Treatment consists of complete obliteration of the extradural AVF by either embolization or surgical excision.[8] It has been reported that after partial obliteration spinal extradural AVFs 
will recruit new blood supplies and make treatment more difficult. For management of Type A spinal extradural AVF it is not mandatory to occlude the intradural draining vein. However, it is necessary to inject embolic material into the entire malformation to achieve complete obliteration.[30]

Improvement of endovascular techniques and agents that are using for embolization of lesions may yield better results in the treatment of extradural AVFs. Recently, Rangel-Castilla used Onyx for the embolization of 7 extradural AVFs. Four patients had excellent recovery at 6-24 months and 3 patients with type A extradural AVF experienced good motor recovery without improvement of bladder/bowel problem.[9]

\section{Author details}

Mohammad R. Rasouli ${ }^{1}$, Vafa Rahimi-Movaghar ${ }^{2,3}$ and Alexander R. Vaccaro ${ }^{1,4}$

1 Rothman Institute of Orthopaedics, Thomas Jefferson University, Philadelphia, PA, USA

2 Sina Trauma and Surgery Research Center, Tehran University of Medical Sciences, Tehran, Iran

3 Department of Neurosurgery, Shariati Hospital, Tehran University of Medical Sciences, Tehran, Iran

4 Departments of Orthopaedic Surgery and Neurological Surgery, Thomas Jefferson University, Philadelphia, PA, USA

\section{References}

[1] Muralidharan R, Saladino A, Lanzino G, Atkinson JL, Rabinstein AA. The clinical and radiological presentation of spinal dural arteriovenous fistula. Spine (Phila Pa 1976). 2011;36:E1641-7.

[2] Spetzler RF, Detwiler PW, Riina HA, Porter RW. Modified classification of spinal cord vascular lesions. J Neurosurg. 2002;96:145-56.

[3] Matushita H, Caldas JG, Texeira MJ. Perimedullary arteriovenous fistulas in children: report on six cases. Childs Nerv Syst. 2012;28:253-64.

[4] Oldfield EH, Doppman JL. Spinal arteriovenous malformations. Clin Neurosurg. 1988;34:161-83.

[5] Westphal M, Koch C. Management of spinal dural arteriovenous fistulae using an interdisciplinary neuroradiological/neurosurgical approach: experience with 47 cases. Neurosurgery. 1999;45:451-7. 
[6] Anson J, Spetzler RF: Classification of spinal arteriovenous malformations and implications of treatment. BNI Q. 1992; 8:2-8.

[7] Toossi S, Josephson SA, Hetts SW, Chin CT, Kralik S, Jun P, Douglas VC. Utility of MRI in spinal arteriovenous fistula. Neurology. 2012;79:25-30.

[8] Takai K, Taniguchi M. Comparative analysis of spinal extradural arteriovenous fistulas with or without intradural venous drainage: a systematic literature review. Neurosurg Focus. 2012;32:E8.

[9] Rangel-Castilla L, Holman PJ, Krishna C, Trask TW, Klucznik RP, Diaz OM. Spinal extradural arteriovenous fistulas: a clinical and radiological description of different types and their novel treatment with Onyx. J Neurosurg Spine. 2011;15:541-9.

[10] Krings T, Mull M, Gilsbach JM, Thron A. Spinal vascular malformations. Eur Radiol. 2005;15:267-78.

[11] Koch C. Spinal dural arteriovenous fistula. Curr Opin Neurol. 2006;19:69-75.

[12] Jellema K, Tijssen CC, van Gijn J. Spinal dural arteriovenous fistulas: a congestive myelopathy that initially mimics a peripheral nerve disorder. Brain. 2006;129:3150-64.

[13] Sivakumar W, Zada G, Yashar P, Giannotta SL, Teitelbaum G, Larsen DW. Endovascular management of spinal dural arteriovenous fistulas. A review. Neurosurg Focus. 2009;26:E15.

[14] Narvid J, Hetts SW, Larsen D, Neuhaus J, Singh TP, McSwain H, Lawton MT, Dowd CF, Higashida RT, Halbach VV. Spinal dural arteriovenous fistulae: clinical features and long-term results. Neurosurgery. 2008;62:159-66.

[15] Eskandar EN, Borges LF, Budzik RF Jr, Putman CM, Ogilvy CS. Spinal dural arteriovenous fistulas: experience with endovascular and surgical therapy. J Neurosurg. 2002 Mar;96:162-7.

[16] Sasaki O, Yajima N, Ichikawa A, Yamashita S, Nakamura K. Deterioration after surgical treatment of spinal dural arteriovenous fistula associated with spinal perimedullary fistula. Neurol Med Chir (Tokyo). 2012;52:516-20.

[17] Takai K, Kin T, Oyama H, Iijima A, Shojima M, Nishido H, Saito N. The use of 3D computer graphics in the diagnosis and treatment of spinal vascular malformations. J Neurosurg Spine. 2011;15:654-9.

[18] Horikoshi T, Hida K, Iwasaki Y, Abe H, Akino M. Chronological changes in MRI findings of spinal dural arteriovenous fistula. Surg Neurol. 2000;53:243-9.

[19] Hetts SW, Moftakhar P, English JD, Dowd CF, Higashida RT, Lawton MT, Douglas VC, Halbach VV. Spinal dural arteriovenous fistulas and intrathecal venous drainage: correlation between digital subtraction angiography, magnetic resonance imaging, and clinical findings. J Neurosurg Spine. 2012;16:433-40. 
[20] Mascalchi M, Ferrito G, Quilici N, Mangiafico S, Cosottini M, Cellerini M, Politi LS, Guerrini L, Bartolozzi C, Villari N. Spinal vascular malformations: MR angiography after treatment. Radiology. 2001;219:346-53.

[21] Afshar JK, Doppman JL, Oldfield EH. Surgical interruption of intradural draining vein as curative treatment of spinal dural arteriovenous fistulas. J Neurosurg. 1995;82:196-200.

[22] Heldner MR, Arnold M, Nedeltchev K, Gralla J, Beck J, Fischer U. Vascular diseases of the spinal cord: a review. Curr Treat Options Neurol. 2012;14:509-20.

[23] Elsberg CA: Diagnosis and Treatment of Surgical Diseases of the Spinal Cord and Its Membranes. London, W.B. Saunders Co., 1916, pp 94-204.

[24] Steinmetz MP, Chow MM, Krishnaney AA, Andrews-Hinders D, Benzel EC, Masaryk TJ, Mayberg MR, Rasmussen PA. Outcome after the treatment of spinal dural arteriovenous fistulae: a contemporary single-institution series and meta-analysis. Neurosurgery. 2004;55:77-87.

[25] Desai A, Bekelis K, Erkmen K. Minimally invasive tubular retractor system for adequate exposure during surgical obliteration of spinaldural arteriovenous fistulas with the aid of indocyanine green intraoperative angiography. J Neurosurg Spine. 2012;17:160-3.

[26] Tacconi L, Lopez Izquierdo BC, Symon L. Outcome and prognostic factors in the surgical treatment of spinal dural arteriovenous fistulas. A long-term study. Br J Neurosurg. 1997;11:298-305.

[27] Doppman JL, Di Chiro G, Ommaya A. Obliteration of spinal-cord arteriovenous malformation by percutaneous embolisation. Lancet. 1968;1:477.

[28] Morgan MK, Marsh WR. Management of spinal dural arteriovenous malformations. J Neurosurg. 1989;70:832-6.

[29] Nogueira RG, Dabus G, Rabinov JD, Ogilvy CS, Hirsch JA, Pryor JC. Onyx embolization for the treatment of spinal dural arteriovenous fistulae: initial experience with longterm follow-up. Technical case report. Neurosurgery. 2009;64:E197-8.

[30] Rangel-Castilla L, Holman PJ, Krishna C, Trask TW, Klucznik RP, Diaz OM. Spinal extradural arteriovenous fistulas: a clinical and radiological description of different types and their novel treatment with Onyx. J Neurosurg Spine. 2011;15:541-9.

[31] Spiotta AM, Hughes G, Masaryk TJ, Hui FK. Balloon-augmented Onyx embolization of a dural arteriovenous fistula arising from the neuromeningeal trunk of the ascending pharyngeal artery: technical report. J Neurointerv Surg. 2011;3:300-3.

[32] Carlson AP, Taylor CL, Yonas H. Treatment of dural arteriovenous fistula using ethylene vinyl alcohol (onyx) arterial embolization as the primary modality: short-term results. J Neurosurg. 2007;107:1120-5.

[33] Schick U, Hassler W. Treatment and outcome of spinal dural arteriovenous fistulas. Eur Spine J. 2003;12:350-5. 
[34] Rubin MN, Rabinstein AA. Vascular diseases of the spinal cord. Neurol Clin. 2013;31:153-81.

[35] Song JK, Vinuela F, Gobin YP, Duckwiler GR, Murayama Y, Kureshi I, Frazee JG, Martin NA. Surgical and endovascular treatment of spinal dural arteriovenous fistulas: longterm disability assessment and prognostic factors. J Neurosurg. 2001;94:199-204.

[36] Djindjian M, Djindjian R, Rey A, Hurth M, Houdart R. Intradural extramedullary spinal arterio-venous malformations fed by the anterior spinal artery. Surg Neurol. $1977 ; 8: 85-93$.

[37] Heros RC, Debrun GM, Ojemann RG, Lasjaunias PL, Naessens PJ. Direct spinal arteriovenous fistula: a new type of spinal AVM. Case report. J Neurosurg. 1986;64:134-9.

[38] Merland JJ, Riche MC, Chiras J. Les fistules artérioveineuses intracanalaires extramédullaires à drainage veineux médullaire. J Neuroradiol. 1980; 7:271-320.

[39] Gueguen B, Merland JJ, Riche MC, Rey A. Vascular malformations of the spinal cord: intrathecal perimedullary arteriovenous fistulas fed by medullary arteries. Neurology. 1987;37:969-79.

[40] Mourier KL, Gobin YP, George B, Lot G, Merland JJ. Intradural perimedullary arteriovenous fistulae: results of surgical and endovascular treatment in a series of 35 cases. Neurosurgery. 1993;32:885-91.

[41] Meng X, Zhang H, Chen Y, Ling F. Traumatic spinal perimedullary arteriovenous fistula: a case report. Acta Neurochir (Wien). 2010;152:1407-10.

[42] Meng X, Zhang H, Wang Y, Ye M, He C, Du J, Ling F. Perimedullary arteriovenous fistulas in pediatric patients: clinical, angiographical, and therapeutic experiences in a series of 19 cases. Childs Nerv Syst. 2010;26:889-96.

[43] Matushita H, Caldas JG, Texeira MJ. Perimedullary arteriovenous fistulas in children: report on six cases. Childs Nerv Syst. 2012;28:253-64.

[44] Cho KT, Lee DY, Chung CK, Han MH, Kim HJ. Treatment of spinal cord perimedullary arteriovenous fistula: embolization versus surgery. Neurosurgery. 2005;56:232-41.

[45] Barrow DL, Colohan AR, Dawson R. Intradural perimedullary arteriovenous fistulas (type IV spinal cord arteriovenous malformations). J Neurosurg. 1994;81:221-9.

[46] Tomlinson FH, Rüfenacht DA, Sundt TM Jr, Nichols DA, Fode NC. Arteriovenous fistulas of the brain and the spinal cord. J Neurosurg. 1993;79:16-27.

[47] Lv X, Li Y, Yang X, Jiang C, Wu Z. Endovascular embolization for symptomatic perimedullary AVF and intramedullary AVM: a series and a literature review. Neuroradiology. 2012;54:349-59 
[48] Mourier KL, Gobin YP, George B, Lot G, Merland JJ. Intradural perimedullary arteriovenous fistulae: results of surgical and endovascular treatment in a series of 35 cases. Neurosurgery. 1993;32:885-91.

[49] Pasqualetto L, Papa R, Isalberti M, Nuzzi NP, Branca V. The endovascular treatment of a spinal perimedullary arteriovenous fistula with coils: a case report. J Neurointerv Surg. 2011;3:88-91.

[50] Oran I, Parildar M, Derbent A. Treatment of slow-flow (type I) perimedullary spinal arteriovenous fistulas with special reference to embolization. AJNR Am J Neuroradiol. 2005;26:2582-6.

[51] Yamamoto S, Kim P, Kurokawa R, Itoki K, Kawamoto S. Selective intraarterial injection of ICG for fluorescence angiography as a guide to extirpate perimedullary arteriovenous fistulas. Acta Neurochir (Wien). 2012;154:457-63.

[52] Murakami T, Koyanagi I, Kaneko T, Iihoshi S, Houkin K. Intraoperative indocyanine green videoangiography for spinal vascular lesions: case report. Neurosurgery. 2011;68:241-5.

[53] Miyoshi Y, Yasuhara T, Nishida A, Tokunaga K, Sugiu K, Date I. Effectiveness of intraoperative near-infrared indocyanine green videoangiography in a case with recurrent spinal perimedullary arteriovenous fistula. Clin Neurol Neurosurg. 2011;113:239-42.

[54] Anderer EG, Kang MM, Moshel YA, Frempong-Boadu A. Successful management of an anterior thoracic Type IV spinal arteriovenous malformation with two associated aneurysms utilizing vertebrectomy. Technical note. J Neurosurg Spine. 2008;9:67-70.

[55] Martin NA, Khanna RK, Batzdorf U. Posterolateral cervical or thoracic approach with spinal cord rotation for vascular malformations or tumors of the ventrolateral spinal cord. J Neurosurg. 1995;83:254-61.

[56] Giese A, Winkler PA, Schichor C, Kantelhardt SR, Boeckh-Behrens T, Tonn JC, Rohde V. A transmedullary approach to occlusion of a ventral perimedullary arteriovenous fistula of the thoracic spinal cord. Neurosurgery. 2010;66:611-5.

[57] Casasco A, Guimaraens L, Senturk C, Cotroneo E, Gigli R, Theron J. Endovascular treatment of cervical giant perimedullary arteriovenous fistulas. Neurosurgery. 2012;70:141-9.

[58] Nagashima C, Miyoshi A, Nagashima R, Ogawa M, Enomoto K, Watabe T. Spinal giant intradural perimedullary arteriovenous fistula: clinical and neuroradiological study in one case with review of literature. Surg Neurol. 1996;45:524-31.

[59] Hida K, Iwasaki Y, Goto K, Miyasaka K, Abe H. Results of the surgical treatment of perimedullary arteriovenous fistulas with special reference to embolization. J Neurosurg. 1999;90:198-205. 